\title{
Erratum to: Processing Speed and Neurodevelopment in Adolescent-Onset Psychosis: Cognitive Slowing Predicts Social Function
}

Peter Bachman • Tara A. Niendam •

Maria Jalbrzikowski • Chan Y. Park • Melita Daley •

Tyrone D. Cannon • Carrie E. Bearden

Published online: 18 March 2012

(C) Springer Science+Business Media, LLC 2012

Erratum to: J Abnorm Child Psychol

DOI 10.1007/s10802-011-9592-5

In the original report, the name of one of the authors was

spelled incorrectly. The correct spelling is Jalbrzikowski.

The online version of the original article can be found at http://dx.doi. org/10.1007/s10802-011-9592-5.

P. Bachman $(\varangle) \cdot$ M. Daley $\cdot$ T. D. Cannon $\cdot$ C. E. Bearden

Semel Institute of Neuroscience \& Human Behavior,

Department of Psychiatry \& Behavioral Sciences,

University of California, Los Angeles,

BOX 951759, 760 Westwood Plaza,

Los Angeles, CA 90095-1759, USA

e-mail: bachman@psych.ucla.edu

T. A. Niendam

Department of Psychiatry and Behavioral Sciences,

University of California - Davis,

Sacramento, CA, USA

M. Jalbrzikowski • C. Y. Park • T. D. Cannon · C. E. Bearden Department of Psychology, University of California - Los Angeles, Los Angeles, CA, USA 